\title{
How polarized is the global income distribution?
}

Roope, Laurence; Niño-Zarazúa, Miguel; Tarp, Finn

Published in:

Economics Letters

DOI:

10.1016/j.econlet.2018.03.013

Publication date:

2018

Document version

Publisher's PDF, also known as Version of record

Document license:

CC BY-NC-ND

Citation for published version (APA):

Roope, L., Niño-Zarazúa, M., \& Tarp, F. (2018). How polarized is the global income distribution? Economics Letters, 167, 86-89. https://doi.org/10.1016/j.econlet.2018.03.013 


\title{
How polarized is the global income distribution?
}

\author{
Laurence Roope $^{\mathrm{a}, *}$, Miguel Niño-Zarazúa ${ }^{\mathrm{b}}$, Finn Tarp ${ }^{\mathrm{b}, \mathrm{c}}$ \\ a Health Economics Research Centre, Nuffield Department of Population Health, University of Oxford, Oxford, OX3 7LF, UK \\ b United Nations University World Institute for Development Economics Research (UNU-WIDER), Helsinki, Finland \\ c Department of Economics, University of Copenhagen, Denmark
}

\section{H I G H L I G H T S}

- First estimates of level of bipolarization of global income distribution.

- Relative bipolarization declined over 1975-2010 but absolute bipolarization went up.

- The trends in global bipolarization mirror those in global inequality.

- The global income distribution is now lognormal rather than twin-peaked.

\section{A R T I C L E I N F O}

\section{Article history:}

Received 16 December 2017

Received in revised form 10 March 2018

Accepted 16 March 2018

Available online 20 March 2018

\section{JEL classification:}

D31

D63

015

\section{Keywords:}

Polarization

Bipolarization

Global polarization

Global inequality

Polarization measures

\begin{abstract}
A B S T R A C T
The interest in the level of global inequality has surged in recent years. This paper complements existing estimates of global inequality by providing the first estimates of the level of bipolarization of the global income distribution. During 1975-2010, global bipolarization declined substantially according to 'relative' measures, while it increased according to 'absolute' measures. The results mirror trends in global inequality over the same period.
\end{abstract}

(C) 2018 UNU-WIDER. Published by Elsevier B.V. This is an open access article under the CC BY-NC-ND license (http://creativecommons.org/licenses/by-nc-nd/4.0/).

\section{Introduction}

In recent years, issues of inequality and globalization, in broad terms, have dominated the global development debate. There is now considerable interest in the economic literature in the level of global interpersonal inequality; that is the level of inequality among all people of the world, ignoring national borders. ${ }^{1}$ Notable recent contributions include Atkinson and Brandolini (2010), Bourguignon and Morrisson (2002), Dowrick and Akmal (2005), Milanovic (2002, 2005, 2012), Niño Zarazúa et al. (2017), Ravallion (2017) and Sala-i Martin (2006). ${ }^{2}$ The underlying methodology

\footnotetext{
* Corresponding author.

E-mail addresses: laurence.roope@dph.ox.ac.uk (L. Roope),

Miguel@wider.unu.edu (M. Niño-Zarazúa), finn@wider.unu.edu (F. Tarp).

1 For an excellent critical review, see Anand and Segal (2008).

2 For historical perspectives, see van Zanden et al. (2014), Firebaugh (2015) and Milanovic (2016).
}

involves constructing a distribution of income of all the citizens of the world, using national accounts and/or survey data. Inequality is subsequently measured based on this global interpersonal distribution of income.

It is now well established that, during the last few decades, income inequality, as captured by standard relative indices such as the Gini coefficient, has declined (Bourguignon, 2017; Milanovic, 2012; Niño Zarazúa et al., 2017). This result is robust even after top incomes are taken into consideration (Jorda and Niño Zarazúa, 2016; Lakner and Milanovic, 2016).

Bosmans et al. (2014) and Niño Zarazúa et al. (2017) extended the analyses of global income trends to include 'absolute' measures. ${ }^{3}$ In contrast to 'relative' inequality measures, 'absolute'

\footnotetext{
3 'Relative' inequality (or polarization) measures are those which are invariant under equiproportional increases in all incomes; 'absolute' inequality (or polarization) measures are those which register no change when the same absolute amount of income is added to all incomes.
} 
measures attach importance to the absolute differences in income that typically arise when economies grow. While used infrequently, there have been growing analyses of the implications of such measures (e.g. Atkinson and Brandolini, 2010; Bosmans et al., 2014; Ravallion, 2003; Subramanian and Jayaraj, 2015). Preference for 'relative' measures vis-a-vis 'absolute' measures is normative. For instance, Amiel and Cowell (1992, 1999a, b), have demonstrated experimentally that people have diverse views regarding how distributions should be ranked with respect to inequality. Niño Zarazúa et al. (2017) found that when global inequality is measured using 'absolute' measures, inequality has increased substantially over the past four decades.

In this study, we extend this body of research by considering a concept related to, but quite distinct from, inequality - namely polarization. Specifically, we focus on bipolarization, as developed by Foster and Wolfson (2010) and Wolfson (1994), and extended by Wang and Tsui (2000). ${ }^{4}$ Bipolarization essentially captures the presence or absence of a middle class. The importance of a large middle class to a healthy society has been recognized since ancient times (Aristotle, $350 \mathrm{BC}$ ). In light of the recent interest in the global income distribution, an analysis of global polarization is timely. We provide a first set of estimates of global (interpersonal) bipolarization.

\section{Measures of bipolarization}

Two characteristics intrinsic to measures of bipolarization are 'non-decreasing spread' and 'non-decreasing bipolarity'. Under non-decreasing spread, a movement of income from the middle to the tails of the income distribution weakly increases bipolarization, which means that as the distribution becomes more spread out from the middle position, bipolarization does not diminish. Nondecreasing bipolarity requires that increased clustering of incomes - either below or above the median - weakly increases bipolarization. Equivalently, a reduction of gaps between any two incomes, both above or both below the median, does not lessen polarization (Chakravarty and D'Ambrosio, 2010).

The key similarities and contrasts between inequality and bipolarization measures are evident from these two criteria. The nondecreasing spread criterion confirms that, like inequality, bipolarization increases under transfers of income from the middle to the tails of the distribution. By contrast, increased clustering of incomes increases polarization, but would decrease any inequality measure satisfying the Pigou-Dalton transfer principle, which deems progressive transfers to be equalizing. Thus, polarization and inequality, though related, are quite distinct concepts.

We employ the following four polarization measures: First, Foster and Wolfson (2010)'s measure, which takes the form:

$P_{F W}=\left(G^{B}-G^{W}\right) \frac{\mu}{m}$

where $\mu$ denotes mean income; $m$ is the median income; $G^{B}$ is the Gini coefficient of a 'smoothed' distribution where all incomes above (respectively, below) $m$ are assigned the mean of those incomes; $G^{W}$ is a population weighted average of the Gini coefficients of actual incomes above and below $m$. Second, the 'absolute' version of this relative bipolarization measure is obtained by multiplying it by the median:

$P_{\text {AFW }}=\left(G^{B}-G^{W}\right) \mu$.

\footnotetext{
4 A second, more general, approach initiated by Esteban and Ray (1994), and extended by Duclos et al. (2004), conceptualizes polarization as clustering around local means of the income distribution, wherever these local means are located.
}

Third, the relative bipolarization measures of Wang and Tsui (2000) are given by:

$P_{W T}=\frac{1}{N} \sum_{i=1}^{N}\left|\frac{x_{i}-m}{m}\right|^{r}$

where individual $i \in\{1, \ldots, N\}$ has income $x_{i} \in \mathbb{R}_{+}$and $r \in$ $(0,1)^{5}$

Fourth, we use an absolute bipolarization measure from a class of measures by Wang and Tsui (2000), which is given by:

$P_{A W T}=\frac{1}{N} \sum_{i=1}^{N}\left|x_{i}-m\right|^{r}$.

\section{Data}

We use data from UNU-WIDER's World Income Inequality Data base (WIID) to construct synthetic global income distributions for six specific years: 1975, 1985, 1995, 2000, 2005 and 2010, following the approach described in Niño Zarazúa et al. (2017). These distributions are built-up from quantile share data for 55 , $86,122,119,135$ and 107 countries in the six respective years. This covers $77 \%$ of the world's population in $1975,85 \%$ in $1985,93 \%$ in $1995,87 \%$ in $2000,94 \%$ in 2005 and $83 \%$ in 2010 . We converted consumption quantile shares into income quantile shares by adjusting the former with the difference between average shares per decile for consumption, and for income. Smooth distributions were then constructed for each country-year using Shorrocks and Wan (2009)'s method. This involved (i) fitting lognormal distributions to the quantile data and generating an equal-weighted synthetic sample of 1,000 observations; (ii) adjusting the values of these observations until the synthetic sample's quantile shares exactly matched the actual ones. The resulting smooth country-year distributions were then scaled up by GDP per capita in 2005 US\$ at purchasing power parity, weighted by population size, and merged into a single synthetic global income distribution.

\section{Results}

Density charts of the global (log) income distribution for each of the six years are provided in Fig. 1. Panel (a) suggests that in 1975 the distribution was a bi-modal normal distribution. This remained so through 1985, 1995 and 2000 (panels (b)-(d), though with the bi-modality becoming steadily less pronounced. Panels (e) and (f) suggest that by 2005 and 2010 the bi-modality had all but disappeared and the distributions appear roughly normal.

This trend is broadly confirmed by each of our relative bipolarization measures, presented in Table 1. Bipolarization is found to decrease dramatically over the period, from 2.534 in 1975 to 0.879 in 2010 according to $P_{F W}$. It also decreased substantially according to $P_{W T}$ for all parameters considered. The decline was strongest for higher values of $r$ which, loosely speaking, are more sensitive to very large deviations of very high incomes from the median. Apart from a very small increase in 2005 according to some relative measures, the decline has been continual and substantial throughout the period analysed.

In stark contrast however, 'absolute' bipolarization is found to have increased substantially, and continually from each period to the next, according to both $P_{A F W}$, and to all parametrizations of $P_{\text {AWT }}$.

\footnotetext{
5 As $r$ increases, this measure attaches greater weight to deviations from $m$ of incomes above $2 \mathrm{~m}$, and less to deviations of incomes below $2 \mathrm{~m}$.
} 


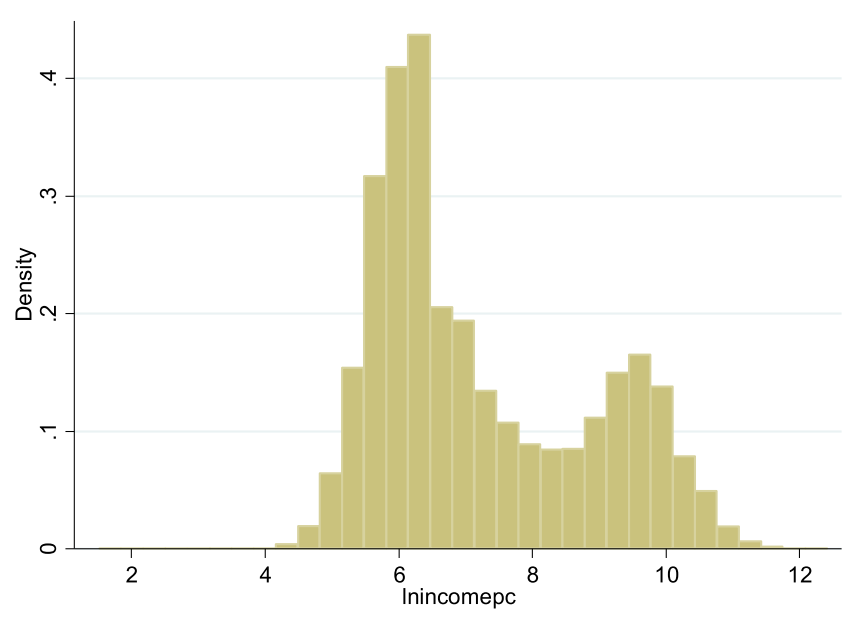

(a) Log income distribution 1975.

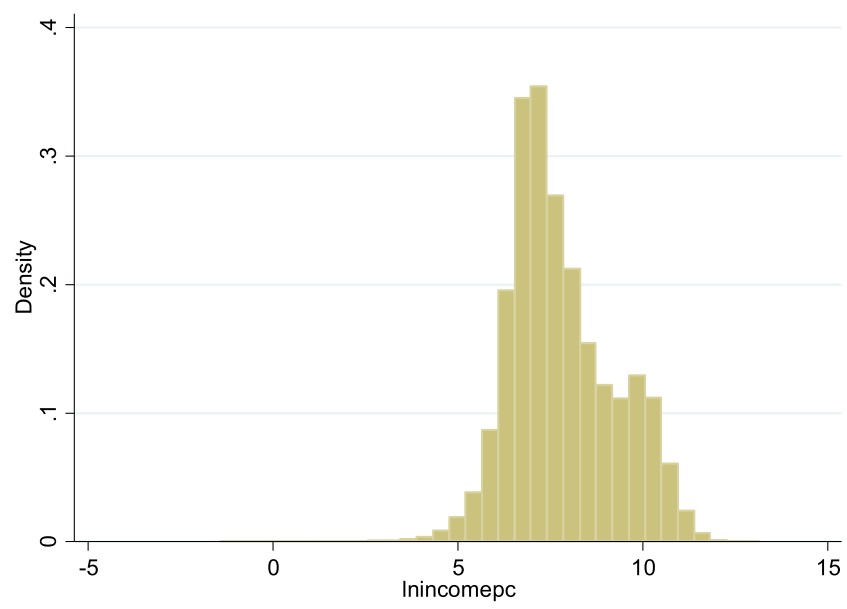

(c) Log income distribution 1995.

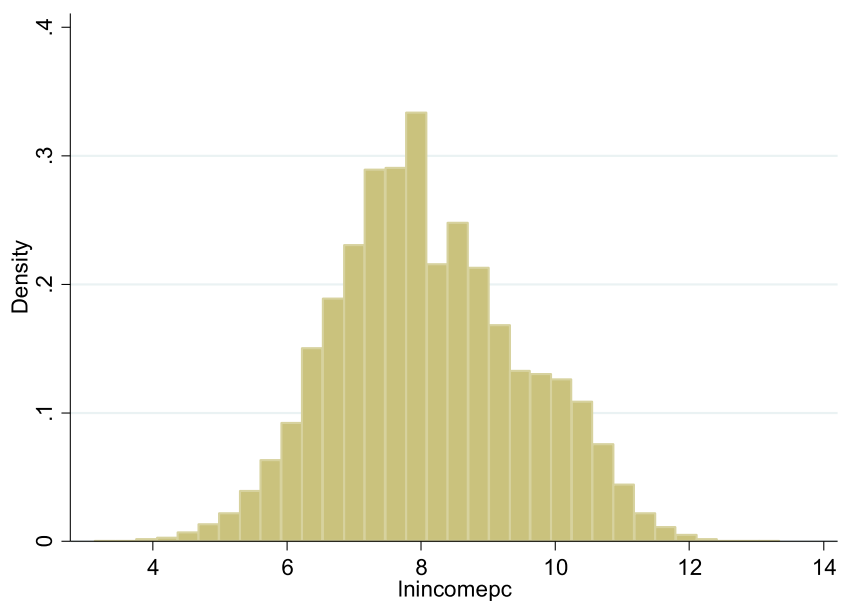

(e) Log income distribution 2005.

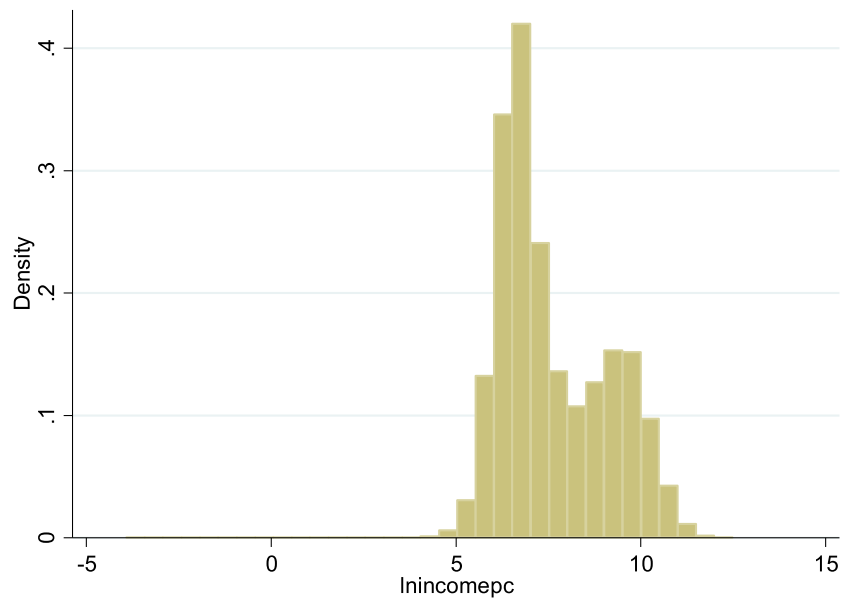

(b) Log income distribution 1985.

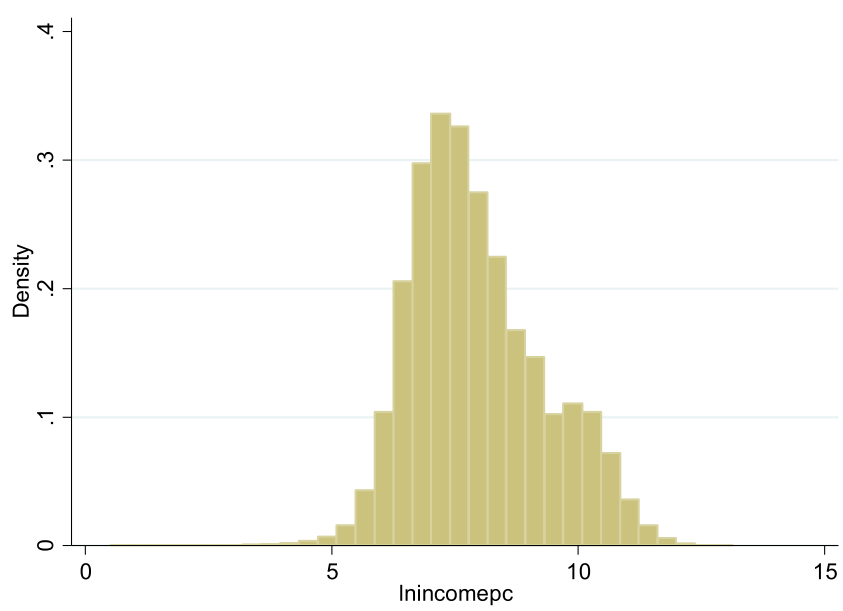

(d) Log income distribution 2000.

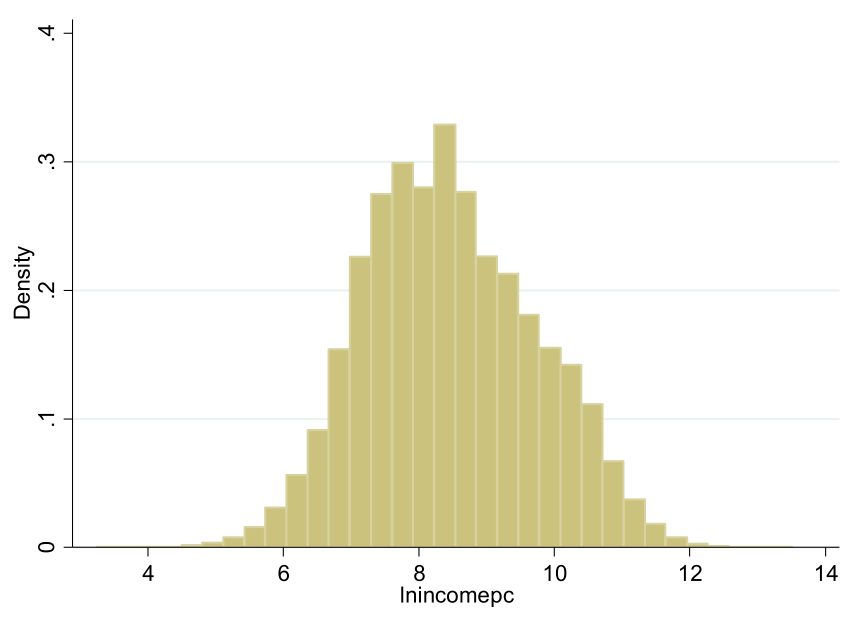

(f) Log income distribution 2010.

Fig. 1. Global log income densities 1975-2010. Source: Authors' estimations based on the WIID.

\section{Conclusions}

National income distributions are typically well approximated as being lognormal (Lopez and Serven, 2006). Our analysis suggests that - following an unprecedented period of globalization and increasing interconnectedness between domestic economies - this is now a good approximation of the global income distribution, which has evolved away from the 'twin peaks' discussed by Quah (1996). Strikingly, the trend in global bipolarization during the period 1975-2010 mirrors Niño Zarazúa et al. (2017)'s results on global inequality: both have steadily decreased in 'relative' terms, but increased in 'absolute' terms. These findings are consistent with a combination of decreasing income gaps between countries, 
Table 1

Bipolarization of global income distribution 1975-2010.

Source: Authors' estimations based on the WIID.

\begin{tabular}{lllllll}
\multicolumn{2}{l}{ Meurce: Authors' estimations based on the WIID. } \\
\hline Measure & 1975 & 1985 & 1995 & 2000 & 2005 & 2010 \\
\hline$P_{\text {FW }}$ & 2.534 & 1.834 & 1.288 & 1.064 & 1.079 & 0.879 \\
$P_{\text {AFW }}$ & 1973.841 & 2296.677 & 2410.121 & 2433.682 & 3033.892 & 3754.136 \\
$P_{W T}$ & & & & & & \\
$r=0.2$ & 1.121 & 1.074 & 1.035 & 1.011 & 1.017 & 0.985 \\
$r=0.4$ & 1.454 & 1.311 & 1.194 & 1.131 & 1.135 & 1.052 \\
$r=0.6$ & 2.158 & 1.801 & 1.536 & 1.405 & 1.390 & 1.213 \\
$r=0.8$ & 3.565 & 2.733 & 2.185 & 1.931 & 1.864 & 1.508 \\
$P_{A W T}$ & & & & & & \\
$r=0.2$ & 4.247 & 4.474 & 4.672 & 4.750 & 4.980 & 5.242 \\
$r=0.4$ & 20.857 & 22.726 & 24.314 & 24.959 & 27.196 & 29.797 \\
$r=0.6$ & 117.219 & 130.025 & 141.156 & 145.623 & 163.088 & 182.907 \\
$r=0.8$ & 733.258 & 821.964 & 906.175 & 939.977 & 1070.524 & 1209.550 \\
\hline
\end{tabular}

causing inequality and polarization to decline in relative terms, and high growth, causing them to increase in absolute terms.

\section{References}

Amiel, Y., Cowell, F., 1992. Measurement of income inequality: Experimental test by questionnaire. J. Public Econ. 47, 3-26.

Amiel, Y., Cowell, F., 1999a. Thinking About Inequality. Cambridge University Press, Cambridge.

Amiel, Y., Cowell, F., 1999b. Income transformations and income inequality. In: Slottje, D. (Ed.), Advances in Econometrics, Income Distribution and Scientific Methodology. Physica Verlag, Heidelberg, pp. 209-232.

Anand, S., Segal, P., 2008. What do we know about global income inequality? J. Econ. Lit. 46, 57-94.

Aristotle, 350 BC. Politics, Vol. 4, Part XI. Trans. Jowett, B. The University of Adelaide. eBooks@Adelaide.

Atkinson, A.B., Brandolini, A., 2010. On analysing the world distribution of income. World Bank Econ. Rev. 24, 1-37.

Bosmans, K., Decancq, A. Decoster, K., 2014. The relativity of decreasing inequality between countries. Economica 81, 276-292.

Bourguignon, F., 2017. The Globalization of Inequality. Princeton University Press, Princeton.

Bourguignon, F., Morrisson, C., 2002. Inequality among world citizens: 1820-1992. Am. Econ. Rev. 92, 727-744.

Chakravarty, S.R., D'Ambrosio, C., 2010. Polarization orderings of income distributions. Rev. Income Wealth 56, 47-64.

Dowrick, S., Akmal, M., 2005. Contradictory trends in global income inequality: A tale of two biases. Rev. Income Wealth 51, 201-229.

Duclos, J.-Y., Esteban, J., Ray, D., 2004. Polarization: Concepts, measurement, estimation. Econometrica 72, 1737-1772.

Esteban, J., Ray, D., 1994. On the measurement of polarization. Econometrica 62, 819-852.

Firebaugh, Glenn, 2015. Global income inequality. In: Scott, Robert A., Kosslyn, Stephen Michael, Buchmann, Marlis C. (Eds.), Emerging Trends in the Social and Behavioral Sciences: An Interdisciplinary, Searchable, and Linkable Resource. John Wiley \& Sons, Inc., New Jersey.

Foster, J.E., Wolfson, M.C., 2010. Polarization and the decline of the middle class: Canada and the U.S. J. Econ. Inequality 8 (2), 247-273.
Jorda, V., Niño Zarazúa, M., 2016. Global inequality: How large is the effect of top incomes? WIDER Working Paper 2016/94 Helsinki: UNU-WIDER.

Lakner, C., Milanovic, B., 2016. Global income distribution: From the fall of the Berlin Wall to the Great Recession. World Bank Econ. Rev. 30, 203-232.

Lopez, J.H., Serven, L., 2006. A Normal Relationship? Poverty, Growth, and Inequality. Vol. 3814. World Bank Publications.

Milanovic, B., 2002. True world income distribution, 1998 and 1993: First calculation based on household surveys alone. Econ. J. 112, 51-92.

Milanovic, B., 2005. Worlds Apart: Measuring International and Global Inequality. Princeton University Press, Princeton and Oxford.

Milanovic, B., 2012. Global inequality recalculated and updated: the effect of new PPP estimates on global inequality and 2005 estimates. J. Econ. Inequal. 10, 118.

Milanovic, B., 2016. Global Inequality. A New Approach for the Age of Globalization. Harvard University Press, Cambridge, Massachusetts.

Niño Zarazúa, M., Roope, L., Tarp, F., 2017. Global inequality: Relatively lower, absolutely higher. Rev. Income Wealth 63 (4), 661-684.

Quah, D., 1996. Two peaks: growth and convergence in models of distribution dynamics. Econ. J. 106, 1045-1055.

Ravallion, M., 2003. The debate on globalization, poverty and inequality: Why measurement matters. Int. Affairs 79, 739-754.

Ravallion, Martin, 2017. Inequality and globalization: A review essay, ECINEQ Working Paper Series 435, Society for the Study of Economic Inequality.

Sala-i Martin, X., 2006. The world distribution of income: Falling poverty and... convergence, period. Q.J. Econ. 121, 351-397.

Shorrocks, A., Wan, G., 2009. Ungrouping income distributions: Synthesizing samples for inequality and poverty analysis. In: Basu, K., Kanbur, R. (Eds.), Arguments for a Better World: Essays in Honor of Amartya Sen , Vol. I, Ethics, Welfare and Measurement. Oxford University Press, Oxford, pp. 414-434.

Subramanian, S., Jayaraj, D., 2015. Growth and Inequality in the Distribution of India's Consumption Expenditure: 1983 to 2009-10, WIDER Working Paper 2015/25 Helsinki: UNU-WIDER.

Wang, Y.-Q., Tsui, K.-Y., 2000. Polarization orderings and new classes of polarization indices. J. Public Econ. Theory 2, 349-363.

van Zanden, J.L., Baten, J., Foldvari, P., van Leeuwen, B., 2014. The changing shape of global inequality 1820-2000; exploring a new dataset. Rev. Income Wealth 60, 279-297.

Wolfson, M.C., 1994. When inequalities diverge. Am. Econ. Rev. 84, 353-358, Papers and Proceedings. 